\title{
Pain Acceptance Creates an Emotional Context That Protects against the Misuse of Prescription Opioids: A Study in a Sample of Patients with Chronic Noncancer Pain
}

\author{
Rosa Esteve (D), Estefanía Marcos, Ángela Reyes-Pérez, Alicia E. López-Martínez $\mathbb{D}$ \\ and Carmen Ramírez-Maestre *(D)
}

Citation: Esteve, R.; Marcos, E.; Reyes-Pérez, Á.; López-Martínez, A.E.; Ramírez-Maestre, C. Pain Acceptance Creates an Emotional Context That Protects against the Misuse of Prescription Opioids: A Study in a Sample of Patients with Chronic Noncancer Pain. Int. J. Environ. Res. Public Health 2021, 18 , 3054. https://doi.org/10.3390/ ijerph18063054

Academic Editor: Paul B. Tchounwou

Received: 10 February 2021

Accepted: 14 March 2021

Published: 16 March 2021

Publisher's Note: MDPI stays neutral with regard to jurisdictional claims in published maps and institutional affiliations.

Copyright: (c) 2021 by the authors. Licensee MDPI, Basel, Switzerland. This article is an open access article distributed under the terms and conditions of the Creative Commons Attribution (CC BY) license (https:// creativecommons.org/licenses/by/ $4.0 /)$.
Facultad de Psicología y Logopedia, Andalucía Tech, Instituto de Investigación Biomédica de Málaga, Universidad de Málaga, 29071 Málaga, Spain; zarazaga@uma.es (R.E.); psicologiaestefi@gmail.com (E.M.); angela_rp_@hotmail.com (Á.R.-P.); aelm@uma.es (A.E.L.-M.)

* Correspondence: cramirez@uma.es; Tel.: +34-952-13-23-89

\begin{abstract}
There is solid evidence of an association between several psychological flexibility processes, particularly pain acceptance, and adaptation to chronic pain. However, there are relatively few studies on the relationship between pain acceptance and opioid misuse in chronic pain patients. Thus, the aim of the present study was to test a hypothetical model in which pain acceptance would regulate pain sensations and pain-related thoughts and emotions, which would be related to opioid misuse. The sample comprised 140 chronic pain patients attending two hospitals. All patients were receiving pharmacological treatment, including opioid analgesics. Structural equation modelling analyses showed a significant association between higher pain acceptance and lower pain intensity and catastrophizing, and lower levels of anxiety and depression. Only higher anxiety and depression were significantly associated with increased opioid misuse. The results suggest that levels of anxiety, depression, and pain acceptance must be assessed before opioids are prescribed. Pain acceptance implies a relationship with internal events that protects against anxiety and depression and thus against opioid misuse. Acceptance and Commitment Therapy appears to be particularly appropriate for these patients.
\end{abstract}

Keywords: opioid prescriptions; pain acceptance; pain catastrophizing; depression; chronic pain; misuse

\section{Introduction}

Chronic pain is a public health problem. In Europe, an estimated $27 \%$ of the general adult population experiences this condition [1]. It has a strong negative impact; is one of the main causes of disability; and entails economic costs higher than those of heart disease, diabetes, and cancer together [2].

Opioid therapy is now used for a broad range of chronic pain conditions [3]. The gradual increase in the use of opioids has become a global phenomenon and is generating social concern. In a 2016 report, the International Narcotics Control Board (INCB) provided data on opioid misuse and its harmful effects [4]. It has been found that the use of long-term opioid treatment increases the risk of death due to unintentional overdose and cardiorespiratory problems [5]. Of note, almost half of the patients entering treatment for opioid use disorder reported that their first exposure to opioids was through a physician's prescription for pain management [6]. We define the misuse of opioids as their use in a manner other than how they are indicated or prescribed [7]. Studies should be conducted on the factors underlying opioid misuse, including psychological ones, because opioid misuse can cause health problems and lead to deadly opioid overdose [8]. In summary, chronic pain and prescription opioid misuse constitute two relevant societal challenges.

From a biopsychosocial perspective, many factors can contribute to understanding the experience of chronic pain, including biophysical, psychological, social, and genetic 
factors, as well as comorbidities [9]. Since the advent of the biopsychosocial model of pain, much research has addressed the role of the psychological factors involved in adjustment to chronic pain [10]. The Cognitive Behavioral (CB) model of pain is a broad framework applied in treating chronic pain [11] and encompasses more specific models, such as the Flexibility Model [12]. Recently, the relevance of studying transdiagnostic psychological factors has been emphasized, including psychological flexibility, which could maintain and exacerbate chronic pain and opioid misuse [13].

Psychological flexibility has been defined as "the ability to contact the present moment more fully as a conscious human being, and to change or persist in behavior when doing so serves valued ends" [14] (p. 7). Acceptance and its opposite, experiential avoidance, are core processes of psychological flexibility $[15,16]$. Experiential avoidance refers to an affect-related regulatory process that involves avoiding upsetting emotions, thoughts, memories, and other private experiences, such that individuals attempt to alter the form and frequency of internal events [17]. In contrast, acceptance implies that individuals actively and consciously welcome these private events and do not attempt to change their frequency or form [14].

As a functional approach, the psychological flexibility model pulls together behaviors that are diverse in their surface features but equivalent in their psychological function. Thus, from this perspective, alcohol and drug abuse are conceived as forms of experiential avoidance since they can contribute to the control or elimination of unwanted private experiences [18]. Several studies have investigated the relationship between experiential avoidance and substance abuse. A specific instrument has even been developed to assess experiential avoidance in persons who misuse substances (i.e., the Acceptance and Action Questionnaire-Substance Abuse [AAQ-SA]) [19]. The Acceptance and Action Questionnaire (AAQ) [20] has been shown to have inadequate internal consistency when used to assess such individuals, and when they have been assessed with the AAQ, it has been shown that experiential avoidance does not mediate Acceptance and Commitment Therapy (ACT) outcomes in addiction [21,22]. The AAQ-SA includes specific items addressing thoughts, feelings, and urges related to substance abuse, has better internal consistency and, people reporting any substance abuse in the last 30 days obtained lower score on the AAQ-SA [19]. Contradictory results have been obtained on the association between experiential avoidance and substance use [23-25], which may be due to the aforementioned limitations of the assessment instruments. Evidence of the relationship between experiential avoidance and substance abuse has been obtained from meta-analyses of the efficacy of ACT [26,27]. In the treatment of substance abuse, significant small to medium effect sizes were obtained with ACT compared to those of active treatment (e.g., Cognitive Behavioral Therapy, pharmacotherapy, 12-step, or standard treatment).

There is considerable evidence supporting an association between several psychological flexibility processes - particularly pain acceptance — and adjustment to chronic pain [12]. Associations have been found between higher pain acceptance and lower levels of anxiety, depression, pain catastrophizing, pain intensity, and disability [28,29]. Moreover, pain acceptance has been associated with lower medication intake [30-34]. This finding is relevant given that there is a growing body of evidence to suggest that prescribed opioid medication misuse is alarmingly frequent in chronic pain patients [35-38].

To our knowledge, relatively few studies have explored the relationship between pain acceptance and opioid misuse in chronic pain patients. A study on a sample of the general population who were experiencing pain and had used painkillers in the month previous to the study found that persons who were less accepting of pain were at more risk of developing opioid dependence [39]. Another study assessed a sample of patients receiving residential addiction treatment for comorbid pain. After controlling for demographic and other risk factors, an association was found between higher pain acceptance and a lower likelihood of developing opiate use disorders [40]. A recent study on a sample of patients recruited from two outpatient pain clinics found that psychological flexibility mediated the association between pain severity and opioid misuse and between pain interference and 
opioid misuse [41]. Due to the paucity of studies and the contradictory results presented in the literature, further research is needed in order to shed light on the relationship between psychological flexibility and opioid misuse in patients with noncancer chronic pain.

Thus, the aim of the present study was to test a hypothetical model in a sample of patients receiving opioid therapy for noncancer chronic pain. Because pain acceptance implies the willingness of patients to come into direct contact with unpleasant experiences such as pain sensations or pain-related thoughts and emotions [42], we postulated that there would be an association between higher pain acceptance and lower pain intensity, lower pain catastrophizing, and lower levels of anxiety and depression [28,29] and an association between higher pain intensity, higher pain catastrophizing, higher anxiety, and depression and increased opioid misuse (i.e., pain acceptance would regulate pain sensations and pain-related thoughts and emotions, which would be associated with opioid misuse).

\section{Materials and Methods}

\subsection{Participants}

All participants were fully informed of the aim of the study and were assured of their personal anonymity and the confidentiality of the survey. Subsequently, their informed consent was obtained to voluntarily participate in the study.

A total of 147 patients were invited to take part in the study. Of these, five refused participation, and two did not meet the inclusion criteria. The recruitment process was conducted from October 2019 to February 2020, which finished at that time due to the COVID-19 lockdown measures. Individuals were considered eligible for inclusion if they met the following criteria: At the moment of participation in the study, they were experiencing pain and had been experiencing pain for at least the last 6 months; they were between 18 and 65 years old; they were not being treated for a malignancy, terminal illness, or psychiatric disorder; they were able to understand the Spanish language; and they were able to understand the instructions and questionnaires. The final sample comprised 140 chronic pain patients attending two hospitals. All participants were receiving pharmacological treatment, including opioid analgesics. In Structural Equation Modelling analyses, sample sizes of at least 10 cases per parameter are considered to be sufficient [43]. Therefore, the final sample size was satisfactory.

The project was conducted in accordance with the Declaration of Helsinki and received ethical clearance by the Institutional Ethics Review Board (ERC UMA-66-2019-H) and the Regional Hospital Ethics Committee.

\subsection{Procedure}

The patients were informed of the study aims, confidentiality was assured, and informed consent was obtained. Each participant then took part in a semi-structured interview with a psychologist to obtain demographic, social, and medical history data. Subsequently, they completed the different questionnaires. Data collection was conducted by two psychologists who had previously been trained in the application of the protocol to ensure the standardization of the assessment process.

\subsection{Variables and Instruments}

\subsubsection{Demographic and Clinical Variables}

Each participant had a semi-structured interview with a psychologist to collect demographic, social, and medical history information.

\subsubsection{Pain Intensity}

The participants were asked to rate their lowest, average, and worst pain during the previous week, as well as their current pain intensity level, on a numerical rating scale (NRS) ranging from 0 ("No pain") to 10 ("Worst pain possible"). These ratings were then averaged into a single composite pain intensity score. Numerical rating scales are 
commonly used in pain research and are known to provide valid and reliable measures of pain intensity across different populations [44].

\subsubsection{Pain Acceptance}

We applied the Spanish version of the questionnaire (CPAQ-SV) [45,46]. This instrument comprises 20 items. It is similar to the original questionnaire and provides a total score and two subscale scores for pain willingness and activity engagement. The CPAQ-SV shows good internal consistency ( $\alpha=0.83$ ). Two studies on the CPAQ-SV [45,47] have supported the validity of the 20-item version. The CPAQ-SV also demonstrates good criterion validity. In this study, the total score showed excellent reliability $(\alpha=0.91)$.

\subsubsection{Pain Catastrophizing}

Catastrophizing is a cognitive process characterized by an expectation of negative outcomes and a lack of confidence and control [48]. It is considered to be a maladaptive coping strategy that intensifies the experience of pain [49].

The 2-item Coping Strategies Questionnaire (CSQ) [50] was used to assess pain catastrophizing. Respondents indicate the frequency with which they experienced two catastrophizing thoughts and feelings when in pain on a 7-point scale ranging from 0 ("Never") to 6 ("Always"). This scale has been shown to provide a valid and reliable measure of catastrophizing when used with chronic pain patients [50]. In the current sample, the standardized alpha coefficient indicated good levels of reliability $(\alpha=0.89)$.

\subsubsection{Anxiety and Depression Symptoms}

The Hospital Anxiety and Depression Scale (HADS) [51,52] is a practical screening tool for identifying and quantifying anxiety and depression in nonpsychiatric patients attending medical outpatient clinics. It comprises 14 items and two subscales: anxiety and depression. Each subscale consists of seven items in which respondents indicate on a 4-point scale the frequency with which they experienced anxiety and depression symptoms. The Spanish version of the scale shows appropriate reliability and validity [52-54]. The internal consistency of both scales is high ( $\alpha=0.86$ for anxiety and $\alpha=0.86$ for depression). In the current sample, the standardized alpha coefficient indicated good levels of reliability ( $\alpha=0.85$ and 0.84 for the anxiety and depression scales, respectively).

\subsubsection{Current Misuse of Prescribed Opioids}

We applied the Spanish translation of the Current Opioid Misuse Measure (COMM) [55,56]. This is a brief patient self-assessment instrument for monitoring chronic pain patients receiving opioid therapy. The COMM comprises 17 items rated from $0=$ "never" to $4=$ "very often". It was developed to track patient status over time, such that the items can be used repeatedly and provide an estimate of the patients" "current" status. Thus, the items refer to a 30 -day time period (i.e., "in the past 30 days,"). We only included behaviors that could change from time to time (i.e., historical items were excluded). Scores on the 17 items are summed to create a total score. A total score of nine or more indicates positive opioid misuse. In the current sample, the standardized alpha coefficient indicated good levels of reliability $(\alpha=0.78)$.

\subsection{Statistical Analyses}

Descriptive statistics were calculated for the sample and study variables. Continuous variables are expressed as means and standard deviations and categorical variables are expressed as numbers and rates. The internal consistency of each instrument was assessed by calculating Cronbach's standardized alpha coefficient for the sample. Cronbach's alpha is used to estimate the proportion of variance that is systematic or consistent in a set of test items. We analyzed correlations between the observed variables included in the model. Finally, the hypothetical model was tested via Structural Equation Modelling (SEM) using LISREL 8.80 software (Scientific Software International Inc., 7383, Loncolnwood, IL, USA). 
A prior check of the data showed that some of the variables were not normally distributed. Thus, we used the Maximum Likelihood estimation method because it is effective for any data distribution if the analyses are performed on covariance matrices and the matrix of fourth-order moments is provided [57]. The following goodness-of-fit indexes were used: the Satorra-Bentler chi-square, the root mean-square error of approximation (RMSEA), the Comparative Fit Index (CFI), and the Non-normed fit index (NNFI). The Satorra-Bentler chi-square is a chi-square fit index that corrects the statistic under distributional violations. To reduce the sensitivity of chi-square to sample size, the index is divided by the degrees of freedom [58]. Ratios of 2 or less are indicative of an acceptable fit of the model [59]. The RMSEA is an absolute misfit index: The closer to zero, the better the fit. Values less than 0.08 indicate an adequate fit $[60,61]$. The CFI and the NNFI range between 0 and 1 : The closer to 1, the better the fit [61]. Pain acceptance was the exogenous variable in the model. The endogenous variables were as follows: anxiety and depression symptoms, pain intensity, pain catastrophizing, and opioid misuse.

\section{Results}

\subsection{Participants}

The final sample comprised 140 chronic pain patients ( 115 women and $25 \mathrm{men}$ ) attending two hospitals. All participants were receiving pharmacological treatment, including opioid analgesics. Mean age was 59.24 years $(\mathrm{SD}=9.77)$ and average pain duration was 17 years $(\mathrm{SD}=13.4)$. The International Association for the Study of Pain classification was applied to determine the type of chronic pain [62]: chronic primary pain (56.4\%), chronic secondary musculoskeletal pain (35.7\%), chronic neuropathic pain (4.3\%), chronic postsurgical or posttraumatic pain (2.9), and chronic secondary headache or orofacial pain $(0.7 \%)$. At the time of the study, $66.4 \%$ of the participants were married, $41.4 \%$ were retired, $17.1 \%$ were unemployed, $22.9 \%$ were homemakers, $55 \%$ had completed primary education, and $29.3 \%$ had completed secondary education. Tramadol $(35.7 \%)$, oxycodone $(15 \%)$, and fentanyl $(14.3 \%)$ were the most frequently used opioid analgesics.

\subsection{Descriptive Statistics}

Table 1 shows the mean scores, standard deviations, and correlation coefficients for all measures.

Table 1. Descriptive statistics and correlations between measures.

\begin{tabular}{cccccccccc}
\hline & $\boldsymbol{M}$ & SD & Range & $\mathbf{1}$ & $\mathbf{2}$ & $\mathbf{3}$ & $\mathbf{4}$ & $\mathbf{5}$ & $\mathbf{6}$ \\
\hline 1. Pain acceptance & 17.39 & 13.78 & $0-46$ & 1 & & & & & \\
2. Anxiety & 19.80 & 5.77 & $7-28$ & $-0.37^{* *}$ & 1 & & & \\
3. Depression & 15.77 & 5.08 & $7-27$ & $-0.55^{* *}$ & $0.55^{* *}$ & 1 & & \\
4. Catastrophizing & 5.47 & 2.18 & $2-8$ & $-0.48^{* *}$ & $0.46^{* *}$ & $0.62 * *$ & 1 & \\
5. Pain intensity & 6.94 & 1.67 & $0-10$ & $-0.35^{* *}$ & $0.22^{*}$ & $0.27^{* *}$ & $0.29 * *$ & 1 & \\
6. Opioid misuse & 15.55 & 8.64 & $0-39$ & $-0.28^{* *}$ & $0.57^{* *}$ & $0.52 * *$ & $0.44^{* *}$ & 0.16 & 1 \\
\hline
\end{tabular}

Note: $M=$ Means; SD = Standard Deviations; Range = Minimum and Maximum scores. ${ }^{* *} p<0.001:{ }^{*} p<0.05$ (Pearson's correlations).

The guidelines proposed by Cohen [63] were used to assess correlations. As shown in Table 1, we found a high negative association between pain acceptance and depression symptoms, a medium negative correlation between pain acceptance and anxiety symptoms, catastrophizing, and pain intensity, and a low negative correlation between pain acceptance and opioid misuse. In contrast, we found a high positive significant correlation between opioid misuse and depression and anxiety symptoms, and a medium positive significant correlation between opioid misuse and pain catastrophizing. Surprisingly, the correlation between opioid misuse and pain intensity did not reach significance. 


\subsection{Structural Equation Modeling}

Table 2 shows the standardized coefficients of the initial model.

Table 2. Initial model. Standardized gamma and beta coefficients.

\begin{tabular}{ccc}
\hline & Pain Acceptance & Opioid Misuse \\
\hline & $\gamma$ & $\beta$ \\
\hline Pain intensity & $-0.27^{*}$ & 0.06 \\
Pain catastrophizing & $-0.36^{*}$ & 0.12 \\
Anxiety & $-0.40^{*}$ & $0.36^{*}$ \\
Depression & $-0.51^{*}$ & $0.25^{*}$ \\
\hline$p<0.05$. & &
\end{tabular}

In order to obtain a parsimonious model of the relationship between the variables and following the recommendations of the Lagrange Multiplier Test [59], we deleted all the non-statistically significant paths of the initial model. Thus, we excluded all paths from pain intensity and pain catastrophizing to prescription opioid misuse.

Figure 1 represents the final model. All path coefficients were statistically significant $(p<0.05)$. The goodness-of-fit indexes calculated for the SEM indicate that the estimated model provides a good fit to the data $\left(\chi^{2}(\mathrm{df})=5.18(6), p=0.52\right.$; RMSEA $=0.00$; NNFI $=1.00$; $\mathrm{CFI}=0.99)$. Figure 1 shows the standardized Beta $(\beta)$ and Gamma $(\gamma)$ coefficients, which can be interpreted as follows: Beta indicates that a change unit in an endogenous variable is associated with beta-change units in another endogenous variable, while all other variables remain constant. Gamma indicates that a change unit in an exogenous variable (pain acceptance) is associated with gamma-change units in an endogenous variable.

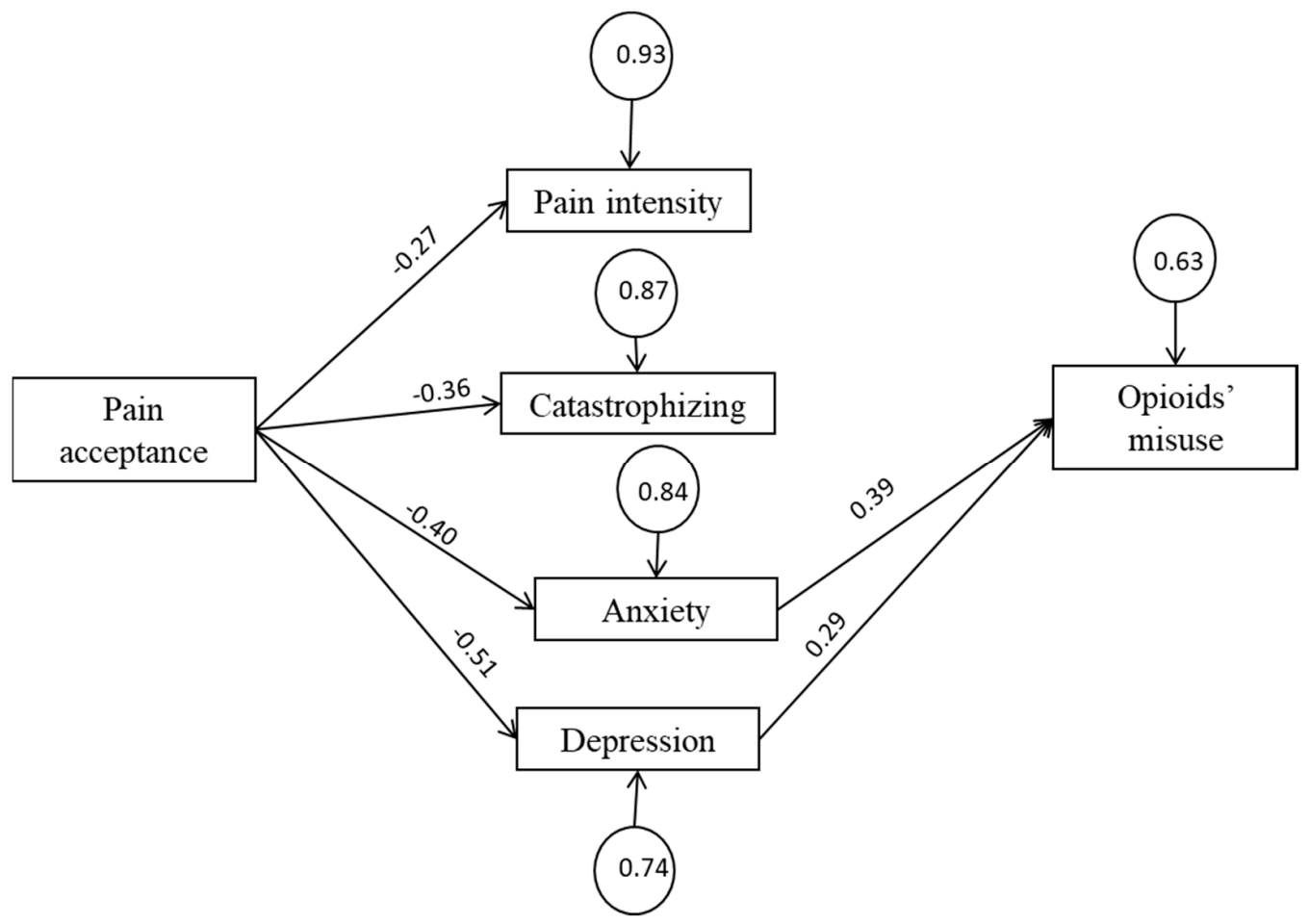

Figure 1. Final model.

Rectangles represent observed variables, circles represent standardized error variances, arrowed lines represent presumed causal paths, values above the arrowed lines represent standardized $\gamma$ and $\beta$ coefficients $(p<0.05)$. Goodness-of-fit indexes of the tested models are as follows: $\chi^{2}(\mathrm{df})=5.18(6), p=0.52 ; \mathrm{RMSEA}=0.00 ; \mathrm{NNFI}=1.00 ; \mathrm{CFI}=0.99$. 
As expected, pain acceptance had four significant and negative path coefficients to pain intensity, pain catastrophizing, depression, and anxiety. However, only depression and anxiety symptoms yielded significant path coefficients to opioid misuse.

\section{Discussion}

Chronic pain is one of the most significant risk factors for opioid misuse [64]. The majority of people who misuse opioids were initially prescribed these drugs for chronic pain and, over time, departed from the initial medical directions $[65,66]$. Thus, it is relevant to investigate the role of the psychological factors involved in adjustment to chronic pain and in opioid misuse. There is ample evidence of an association between psychological flexibility processes, particularly pain acceptance, and better adjustment to pain $[12,28,29]$ and preliminary evidence of an association between pain acceptance and a lower risk of opioid misuse in chronic pain patients [39-41]. Thus, the present study tested a hypothetical model in which pain acceptance would regulate the experience of pain, including pain intensity, catastrophic pain-related thoughts and emotions, and anxiety and depression. All of these factors are associated with opioid misuse. The results partially supported the postulated model. In particular, a significant association was found between higher pain acceptance and lower pain intensity, lower pain catastrophizing, and lower levels of anxiety and depression. Only higher levels of anxiety and depression were significantly associated with increased opioid misuse. These results are in line with a well-documented finding in the literature: Pain acceptance, defined as the response to pain-related experiences without attempts at control or avoidance and engaging in normal life activities even if pain is present [42], effectively regulates the experience of pain $[12,28,29]$ and, indirectly, opioid misuse through anxiety and depression.

Interestingly, we found no association between self-reported pain intensity and opioid misuse. This finding is compatible with those of previous cross-sectional and longitudinal studies [67-70], which found that self-reported pain intensity contributed minimally to opioid craving. This variable is associated with prescription opioid misuse in chronic pain patients receiving long-term opioid therapy $[67,71]$. A recent longitudinal study found that the association between pain intensity and opioid misuse disappeared when controlling for negative affect and pain catastrophizing [72]. Instead, and in line with our results, a significant association has been found between the severity of prescription opioid misuse and self-reported anxiety and depression [67]. These results challenge the intuitive assumption that patients crave opioid medication due to pain and the relief that they expect to obtain, and instead suggest that opioid misuse is aimed at mitigating unpleasant emotional states.

Several studies have found an association between general measures of prescription opioid misuse and pain catastrophizing, defined as ruminating thoughts about the serious threat that pain represents and the lack of personal resources for coping with it [73-77]. Furthermore, an association has been found between increased pain catastrophizing and an increased likelihood of running out of opioid medication early, even after controlling for the patients' levels of pain intensity and negative affect [72]. Pain catastrophizing has also been associated with increased cravings for prescription opioids [78]. This study found no evidence of an association between pain catastrophizing and opioid misuse. This finding is similar to that of a previous study [79]. The authors explained the discrepancy between the results and those of previous research in terms of the composition of their sample, which they judged to be more heterogeneous and representative of the population of patients treated at a tertiary pain clinic than samples investigated in previous studies. The discrepancy between our results and those reported in previous studies could be due to the assessment tool we used to measure pain catastrophizing. Previous studies have used the Pain Catastrophizing Scale [80], whereas we used the 2-item CSQ [50]. Although these items proved to be valid and reliable, as their authors recognize, they do not completely capture the entire content domain of the catastrophizing construct, which comprises the aforementioned dimensions of rumination, magnification, and helplessness [80]. 
The results of the present study suggest that anxiety and depression are associated with the misuse of prescription opioids in patients receiving opioid therapy. The relationship between anxiety and depression and substance abuse in general [81] and opioid misuse in particular is a well-documented finding [82,83]; there is also considerable evidence on the comorbidity of chronic pain and mood disorders [84]. Previous studies have consistently found that patients with high levels of anxiety and depression receiving opioid treatment for chronic pain are at increased risk of developing opioid misuse [80-90]. In fact, theories of addiction propose that escape from and avoidance of negative affect is the predominant motive for addictive drug use [91,92]. This perspective suggests that the mechanism sustaining opioid addiction could be a learned association between opioids and relief from an existing dysphoric state, which is formed and maintained by negative reinforcement $[93,94]$. In order to understand the mechanisms underlying the association between opioid-related and anxiety-related disorders, recent research has addressed transdiagnostic vulnerability factors [95], and specifically, anxiety sensitivity [96], emotion dysregulation [97], pain-anxiety [89], distress intolerance [98], and acceptance [39-41] as in the present study. All these factors refer to maladaptive responses to emotional states that are mainly characterized by avoidance, although there is some degree of overlap between them. Thus, there is a need for these results to be integrated into an overarching theoretical model. In this regard, the Psychological Flexibility Model [14] is promising. Until now, most related studies have focused on acceptance and experiential avoidance. Future research could address the role of all the elements of the model in relation to co-morbid anxiety and depression and opioid misuse in chronic pain patients.

A research study [99] found that some of the factors associated with opioid misuse are similar to those associated with opioid prescription. In a sample of patients with noncancer chronic pain, the participants who were prescribed opioids were older, reported higher levels of pain intensity and depressive symptoms and reported lower levels of pain-acceptance than those who had not been prescribed opioids. It could be the case that physicians prescribe opioids more frequently to those patients who are at greater risk of opioid misuse. A future line of research would be to simultaneously study the factors involved in the prescription of opioids and the factors involved in their misuse in the same group of participants.

The current study has limitations. Firstly, the exclusive reliance on self-report measures could have influenced the results due to shared methodological variance. Secondly, the cross-sectional nature of the design precludes drawing causal inferences. Thirdly, the capacity to generalize the results of this study might be limited by the characteristics of the sample: Women were overrepresented; all the participants had long-lasting musculoskeletal pain; their level of education level was low, and most of them were no longer active workers. Finally, future studies could investigate the differential effect of different types of opioid medications.

This study has relevant clinical implications. Firstly, in order to halt the alarming spread of opioid misuse, anxiety, depression, and pain acceptance should be assessed in patients as a priority when prescribing opioids. In addition, patients with significant levels of depression and anxiety and low levels of pain acceptance should be carefully monitored by clinicians. Secondly, since our findings and those of other studies suggest that anxiety and depression are related to opioid misuse, Cognitive Behavioral Therapy [11] and, specifically, ACT [100], which promotes pain acceptance, appear to be particularly appropriate as adjunctive therapy to standard treatment for these patients.

\section{Conclusions}

Patients who are able to accept their pain-related sensations, thoughts, and emotions will experience lower levels of anxiety and depression, and thus will be at a lower risk of opioid misuse. Anxiety, depression, and pain acceptance should therefore be routinely assessed before opioids are prescribed. Psychological interventions may be needed when 
depression, anxiety, and low levels of pain acceptance are detected. Clinicians should be extremely cautious when prescribing opioids to these patients.

Author Contributions: Conceptualization, C.R.-M., R.E., and A.E.L.-M.; data curation, E.M. and Á.R.-P.; funding acquisition, C.R.-M. and A.E.L.-M.; investigation, C.R.-M., R.E., and A.E.L.-M.; methodology, C.R.-M., R.E., and A.E.L.-M.; visualization, Á.R.-P. and E.M.; writing—original draft, R.E. and C.R.-M.; writing - review and editing, C.R.-M., R.E., A.E.L.-M., E.M., and Á.R.-P. All authors have read and agreed to the published version of the manuscript.

Funding: This study was supported by grants from the Spanish Ministry of Science and Innovation (PID2019-106086RB-I00) and the Regional Government of Andalusia (HUM-566).

Institutional Review Board Statement: The project was conducted in accordance with the Declaration of Helsinki and received ethical clearance by the Institutional Ethics Review Board (ERC UMA) and the Regional Hospital Ethics Committee.

Informed Consent Statement: Informed consent was obtained from all subjects involved in the study.

Data Availability Statement: Not applicable.

Conflicts of Interest: The authors declare no conflict of interest.

\section{References}

1. Leadley, R.M.; Armstrong, N.; Lee, Y.C.; Allen, A.; Kleijnen, J. Chronic diseases in the European Union: The prevalence and health cost implications of chronic pain. J. Pain Palliat. Care Pharmacother. 2012, 26, 310-325. [CrossRef] [PubMed]

2. Gaskin, D.J.; Richard, P. The economic costs of pain in the United States. J. Pain 2012, 13, 715-724. [CrossRef] [PubMed]

3. Els, C.; Jackson, T.D.; Kunyk, D.; Lappi, V.G.; Sonnenberg, B.; Hagtvedt, R.; Sharma, S.; Kolahdooz, F.; Straube, S. Adverse events associated with medium-and long-term use of opioids for chronic non-cancer pain: An overview of Cochrane Reviews. Cochrane Database Syst. Rev. 2017, 10, CD012509. [CrossRef] [PubMed]

4. Berterame, S.; Erthal, J.; Thomas, J.; Fellner, S.; Vosse, B.; Clare, P.; Hao, W.; Johnson, D.T.; Mohar, A.; Pavadia, J.; et al. Use of and barriers to access to opioid analgesics: A worldwide, regional, and national study. Lancet 2016, 387, 1644-1656. [CrossRef]

5. Ray, W.A.; Chung, C.P.; Murray, K.T.; Hall, K.; Stein, C.M. Prescription of long-acting opioids and mortality in patients with chronic noncancer pain. JAMA 2016, 315, 2415-2423. [CrossRef]

6. Cicero, T.J.; Ellis, M.S.; Kasper, Z.A. Psychoactive substance use prior to the development of iatrogenic opioid abuse: A descriptive analysis of treatment-seeking opioid abusers. Addict. Behav. 2017, 65, 242-244. [CrossRef]

7. Savage, S.R.; Joranson, D.E.; Covington, E.C.; Schnoll, S.H.; Heit, H.A.; Gilson, A.M. Definitions related to the medical use of opioids: Evolution towards universal agreement. J. Pain Symptom Manag. 2003, 26, 655-667. [CrossRef]

8. Kertesz, S.G.; Gordon, A.J. A crisis of opioids and the limits of prescription control: United States. Addiction 2019, 114, 169-180. [CrossRef]

9. Turk, D.C.; Monarch, E.S. Biopsychosocial perspective on chronic pain. In Psychological Approaches to Pain Management: A Practitioner's Handbook; Turk, D., Gatchel, R.J., Eds.; Guilford Press: New York, NY, USA, 2002; pp. 3-29.

10. Bevers, K.; Watts, L.; Kishino, N.D.; Gatchel, R.J. The biopsychosocial model of the assessment, prevention, and treatment of chronic pain. US Neurol. 2016, 12, 98-104. [CrossRef]

11. Williams, A.C.; Fisher, E.; Hearn, L.; Eccleston, C. Psychological therapies for the management of chronic pain (excluding headache) in adults. Cochrane Database Syst. Rev. 2020, 8, CD007407. [CrossRef]

12. McCracken, L.M.; Morley, S. The psychological flexibility model: A basis for integration and progress in psychological approaches to chronic pain management. J. Pain 2014, 15, 221-234. [CrossRef]

13. Ditre, J.W.; Zale, E.L.; LaRowe, L.R. A reciprocal model of pain and substance use: Transdiagnostic considerations, clinical implications, and future directions. Ann. Rev. Clin. Psychol. 2019, 15, 503-528. [CrossRef]

14. Hayes, S.C.; Luoma, J.B.; Bond, F.W.; Masuda, A.J. Acceptance and commitment therapy: Model, processes and outcomes. Behav. Res. Ther. 2006, 44, 1-25. [CrossRef]

15. Hayes, S.C.; Follette, V.M.; Linehan, M.M. Mindfulness and Acceptance: Expanding the Cognitive-Behavioral Tradition, 1st ed.; Guilford Press: New York, NY, USA, 2004.

16. Levin, M.E.; Hildebrandt, M.J.; Lillis, J.; Hayes, S.C. The impact of treatment components suggested by the psychological flexibility model: A meta-analysis of laboratory-based component studies. Behav. Ther. 2012, 43, 741-756. [CrossRef]

17. Hayes, S.C.; Wilson, K.G.; Gifford, E.; Follette, V.M.; Strosahl, K.D. Emotional avoidance and behavior disorders: A functional dimensional approach to diagnosis and treatment. J. Consult Clin. Psychol. 1996, 64, 1152-1168. [CrossRef]

18. Wilson, K.G.; Hayes, S.C.; Byrd, M.R. Exploring compatibilities between acceptance and commitment therapy and 12-step treatment for substance abuse. J. Ration. Emot. Cogn. Behav. Ther. 2000, 18, 209-234. [CrossRef]

19. Luoma, J.; Drake, C.E.; Kohlenberg, B.S.; Hayes, S.C. Substance abuse and psychological flexibility: The development of a new measure. Addict. Res. Theory 2011, 19, 3-13. [CrossRef] 
20. Hayes, S.C.; Strosahl, K.; Wilson, K.G.; Bissett, R.T.; Pistorello, J.; Toarmino, D.; Polusny, M.A.; Dykstra, T.A.; Batten, S.V.; Bergan, J.; et al. Measuring experiential avoidance: A preliminary test of a working model. Psychol. Rec. 2004, 54, 553-578. [CrossRef]

21. Bissett, R.T. Processes of change: Acceptance versus 12-step in polysubstance-abusing methadone clients. ProQuest Inf. Learn. 2002, 63, 10146.

22. Luoma, J.B.; Kohlenberg, B.S.; Hayes, S.C.; Bunting, K.; Rye, A.K. Reducing self-stigma in substance abuse through acceptance and commitment therapy: Model, manual development, and pilot outcomes. Addict. Res. Theory 2008, 16, 149-165. [CrossRef] [PubMed]

23. Kingston, J.; Clarke, S.; Remington, B. Experiential avoidance and problem behavior: A mediational analysis. Behav. Modif. 2010, 34, 145-163. [CrossRef]

24. Levin, M.E.; Lillis, J.; Seeley, J.; Hayes, S.C.; Pistorello, J.; Biglan, A. Exploring the relationship between experiential avoidance, alcohol use disorders, and alcohol-related problems among first year college students. J. Am. Coll. Health 2012, 60, 443-448. [CrossRef]

25. Serowik, K.L.; Orsillo, S.M. The relationship between substance use, experiential avoidance, and personally meaningful experiences. Subst. Use Misuse 2019, 54, 1834-1844. [CrossRef]

26. Lee, E.B.; An, W.; Levin, M.E.; Twohig, M.P. An initial meta-analysis of Acceptance and Commitment Therapy for treating substance use disorders. Drug Alcohol Depend. 2015, 155, 1-7. [CrossRef] [PubMed]

27. Öst, L.G. The efficacy of acceptance and commitment therapy: An updated systematic review and meta-analysis. Behav. Res. Ther. 2014, 61, 105-121. [CrossRef]

28. de Boer, M.J.; Steinhagen, H.E.; Versteegen, G.J.; Struys, M.M.; Sanderman, R. Mindfulness, acceptance and catastrophizing in chronic pain. PLoS ONE 2014, 9, e87445. [CrossRef]

29. McCracken, L.M.; Vowles, K.E. Acceptance of chronic pain. Curr. Pain Headache Rep. 2006, 10, 90-94. [CrossRef]

30. Esteve, R.; López-Martínez, A.E.; Ruíz-Párraga, G.T.; Serrano-Ibáñez, E.R.; Ramírez-Maestre, C. Pain Acceptance and Pain-Related Disability Predict Healthcare Utilization and Medication Intake in Patients with Non-Specific Chronic Spinal Pain. Int. J. Environ. Res. Public Health 2020, 17, 5556. [CrossRef] [PubMed]

31. McCracken, L.M.; Eccleston, C. A prospective study of acceptance of pain and patient functioning with chronic pain. Pain 2005, 118, 164-169. [CrossRef] [PubMed]

32. McCracken, L.M.; Vowles, K.E. A prospective analysis of acceptance of pain and values-based action in patients with chronic pain. Health Psychol. 2008, 27, 215-220. [CrossRef] [PubMed]

33. McCracken, L.M.; Vowles, K.E.; Gauntlett-Gilbert, J. A prospective investigation of acceptance and control-oriented coping with chronic pain. J. Behav. Med. 2007, 30, 339-349. [CrossRef]

34. McCracken, L.M.; Vowles, K.E.; Zhao-O'Brien, J. Further development of an instrument to assess psychological flexibility in people with chronic pain. J. Behav. Med. 2010, 33, 346-354. [CrossRef]

35. Chou, R.; Turner, J.A.; Devine, E.B.; Hansen, R.N.; Sullivan, S.D.; Blazina, I.; Dana, T.; Bougatsos, C.; Deyo, R.A. The effectiveness and risks of long-term opioid therapy for chronic pain: A systematic review for a National Institutes of Health Pathways to Prevention Workshop. Ann. Intern. Med. 2015, 162, 276-286. [CrossRef]

36. Højsted, J.; Sjøgren, P. Addiction to opioids in chronic pain patients: A literature review. Eur. J. Pain 2007, 11, 490-518. [CrossRef]

37. Kaye, A.D.; Jones, M.R.; Kaye, A.M.; Ripoll, J.G.; Jones, D.E.; Galan, V.; Beakley, B.D.; Calixto, F.; Bolden, J.L.; Urman, R.D.; et al. Prescription opioid abuse in chronic pain: An updated review of opioid abuse predictors and strategies to curb opioid abuse (part 2). Pain Physician 2017, 20, S111-S133.

38. Volkow, N.; Benveniste, H.; McLellan, A.T. Use and misuse of opioids in chronic pain. Ann. Rev. Med. 2018, 69, 451-465. [CrossRef] [PubMed]

39. Elander, J.; Duarte, J.; Maratos, F.A.; Gilbert, P. Predictors of painkiller dependence among people with pain in the general population. Pain Med. 2014, 15, 613-624. [CrossRef] [PubMed]

40. Lin, L.A.; Bohnert, A.S.; Price, A.M.; Jannausch, M.; Bonar, E.E.; Ilgen, M.A. Pain acceptance and opiate use disorders in addiction treatment patients with comorbid pain. Drug Alcohol Depend. 2015, 157, 136-142. [CrossRef]

41. Rhodes, A.; Marks, D.; Block-Lerner, J.; Lomauro, T. Psychological Flexibility, Pain Characteristics and Risk of Opioid Misuse in Noncancerous Chronic Pain Patients. J. Clin. Psychol. Med. Settings 2020. [CrossRef] [PubMed]

42. McCracken, L.M. Toward understanding acceptance and psychological flexibility in chronic pain. Pain 2010, 149, 420-421. [CrossRef]

43. Jackson, D.L. Revisiting sample size and number of parameter estimates: Some support for the N: Q hypothesis. Struct. Equ. Modeling 2003, 10, 128-141. [CrossRef]

44. Jensen, M.; Karoly, P. Self-Report Scales and Procedures for Assessing Pain in Adults. In Handbook of Pain Assessment; Turk, D., Melzack, R., Eds.; Guilford Press: New York, NY, USA, 2001; pp. 15-34.

45. Bendayan, R.; Esteve, R.; Blanca, M.J. New Empirical Evidence of the Validity of the Chronic Pain Acceptance Questionnaire: The Differential Influence of Activity Engagement and Pain Willingness on Adjustment to Chronic Pain. Br. J. Health Psychol. 2012, 17, 314-326. [CrossRef] [PubMed]

46. MCracken, L.M.; Vowles, K.E.; Eccleston, C. Acceptance of Chronic Pain: Component Analysis and a Revised Assessment Method. Pain 2004, 107, 159-166. [CrossRef] [PubMed] 
47. Rodero, B.; García-Campayo, J.; Casanueva, B.; del Hoyo, Y.L.; Serrano-Blanco, A.; Luciano, J.V. Validation of the Spanish Version of the Chronic Pain Acceptance Questionnaire (CPAQ) for the Assessment of Acceptance in Fibromyalgia. Health Qual. Life Outcomes 2010, 8, 37. [CrossRef] [PubMed]

48. Chaves, J.E.; Brown, J.M. Spontaneous cognitive strategies for the control of clinical pain and stress. J. Behav. Med. 1987, 10, 263-276. [CrossRef]

49. Rosenstiel, A.K.; Keefe, E.J. The use of coping strategies in chronic low back pain patients: Relationship to patient characteristics and current adjustment. Pain 1983, 17, 33-44. [CrossRef]

50. Jensen, M.; Keefe, F.; Lefebvre, J.; Romano, J.; Turner, J. One-and Two-Item Measures of Pain Beliefs and Coping Strategies. Pain 2003, 104, 453-459. [CrossRef]

51. Zigmond, A.S.; Snaith, R.P. The Hospital Anxiety and Depression Scale. Acta Psychiatr. Scand. 1983, 67, 361-370. [CrossRef]

52. Quintana, J.M.; Padierna, A.; Esteban, C.; Arostegui, I.; Bilbao, A.; Ruiz, I. Evaluation of the Psychometric Characteristics of the Spanish Version of the Hospital Anxiety and Depression Scale. Acta Psychiatr. Scand. 2003, 107, 216-221. [CrossRef]

53. Herrero, M.J.; Blanch, J.; Peri, J.M.; De Pablo, J.; Pintor, L.; Bulbena, A. A validation study of the hospital anxiety and depression scale (HADS) in a Spanish population. Gen. Hosp. Psychiatry 2003, 25, 277-283. [CrossRef]

54. Terol-Cantero, M.C.; Cabrera-Perona, V. Hospital Anxiety and Depression Scale (HADS) review in Spanish Samples. Anales Psicología 2015, 31, 494. [CrossRef]

55. Butler, S.; Budman, S.; Fernandez, K.; Houle, B.; Benoit, C.; Katz, N.; Jamison, R. Development and Validation of the Current Opioid Misuse Measure. Pain 2007, 130, 144-156. [CrossRef] [PubMed]

56. Butler, S.; Budman, S.; Fanciullo, G.; Jamison, R. Cross Validation of the Current Opioid Misuse Measure (COMM) to Monitor Chronic Pain Patients on Opioid Therapy. Clin. J. Pain 2010, 26, 770-776. [CrossRef] [PubMed]

57. Batista, J.; Coenders, G. Modelos de Ecuaciones Estructurales; La Muralla: Madrid, España, 2000.

58. Bentler, P.M. Comparative Fit Indexes in Structural Models. Psychol. Bull. 1990, 107, 238. [CrossRef] [PubMed]

59. Kline, R. Principles and Practice of Structural Equation Modelling, 3rd ed.; Guilford Press: New York, NY, USA, 2005.

60. Hu, L.T.; Bentler, P.M. Fit Indices in Covariance Structure Modeling: Sensitivity to Underparameterized Model Misspecification. Psychol. Methods 1998, 3, 424-453. [CrossRef]

61. Hu, L.-T.; Bentler, P.M. Structural Equation Modeling: A Multidisciplinary Journal Cutoff Criteria for Fit Indexes in Covariance Structure Analysis: Conventional Criteria versus New Alternatives. Multidiscip J. 2009, 6, 1-55. [CrossRef]

62. Treede, R.-D.; Rief, W.; Barke, A.; Aziz, Q.; Bennett, M.I.; Benoliel, R.; Cohen, M.; Evers, S.; Finnerup, N.B.; First, M.B.; et al. Chronic pain as a symptom or a disease: The IASP Classification of Chronic Pain for the International Classification of Diseases (ICD-11). Pain 2019, 160, 19-27. [CrossRef]

63. Cohen, J. Statistical Power Analysis for the Behavioral Sciences, 2nd ed.; Lawrence Erlbaum Associates Inc.: Hillsdale, NJ, USA, 1988.

64. Dowell, D.; Haegerich, T.; Chou, R. CDC Guidelines for Prescribing Opioids for Chronic Pain—United States, 2016. JAMA 2016, 315, 1624-1645. [CrossRef]

65. Blanco, C.; Wall, M.M.; Okuda, M.; Wang, S.; Iza, M.; Olfson, M. Pain as a Predictor of Opioid Use Disorder in a Nationally Representative Sample. Am. J. Psychiatry 2016, 173, 1189-1195. [CrossRef]

66. Novak, S.P.; Glasheen, C.; Roland, C.L. Prescription pain reliever misuse and levels of pain impairment: 3-year course in a nationally representative outpatient sample of US adults. Subst. Abuse Rehabil. 2016, 7, 87-98. [CrossRef]

67. Martel, M.O.; Dolman, A.J.; Edwards, R.R.; Jamison, R.N.; Wasan, A.D. The association between negative affect and prescription opioid misuse in patients with chronic pain: The mediating role of opioid craving. J. Pain 2014, 15, 90-100. [CrossRef] [PubMed]

68. Martel, M.O.; Finan, P.H.; McHugh, R.K.; Issa, M.; Edwards, R.R.; Jamison, R.N.; Wasan, A.D. Day-to-day pain symptoms are only weakly associated with opioid craving among patients with chronic pain prescribed opioid therapy. Drug Alcohol Depend. 2016, 162, 130-136. [CrossRef] [PubMed]

69. Garland, E.L.; Brown, S.M.; Howard, M.O. Thought suppression as a mediator of the association between depressed mood and prescription opioid craving among chronic pain patients. J. Behav. Med. 2016, 39, 128-138. [CrossRef] [PubMed]

70. Wasan, A.D.; Ross, E.L.; Michna, E.; Chibnik, L.; Greenfield, S.F.; Weiss, R.D.; Jamison, R.N. Craving of prescription opioids in patients with chronic pain: A longitudinal outcomes trial. J. Pain 2012, 13, 146-154. [CrossRef]

71. Wasan, A.D.; Butler, S.F.; Budman, S.H.; Fernandez, K.; Weiss, R.D.; Greenfield, S.F.; Jamison, R.N. Does report of craving opioid medication predict aberrant drug behavior among chronic pain patients? Clin. J. Pain 2009, 25, 193-198. [CrossRef]

72. Martel, M.O.; Edwards, R.R.; Jamison, R.N. The relative contribution of pain and psychological factors to opioid misuse: A 6-month observational study. Am. Psychol. 2020, 75, 772-783. [CrossRef]

73. Edwards, R.R.; Wasan, A.D.; Michna, E.; Greenbaum, S.; Ross, E.; Jamison, R.N. Elevated pain sensitivity in chronic pain patients at risk for opioid misuse. J. Pain 2011, 12, 953-963. [CrossRef]

74. Ferrari, R.; Capraro, M.; Visentin, M. Risk factors in opioid treatment of chronic noncancer pain: A multidisciplinary assessment. In Pain Management: Current Issues and Opinions; Gabor, B., Noe, C.E., Eds.; Intech: Rijeka, Croatia, 2012; pp. 419-459.

75. Jamison, R.N.; Link, C.L.; Marceau, L.D. Do pain patients at high risk for substance misuse experience more pain? A longitudinal outcomes study. Pain Med. 2009, 10, 1084-1094. [CrossRef]

76. Martel, M.O.; Wasan, A.D.; Jamison, R.N.; Edwards, R.R. Catastrophic thinking and increased risk for prescription opioid misuse in patients with chronic pain. Drug Alcohol Depend. 2013, 132, 335-341. [CrossRef] 
77. Morasco, B.J.; Dobscha, S.K. Prescription medication misuse and substance use disorder in VA primary care patients with chronic pain. Gen. Hosp. Psychiatry 2008, 30, 93-99. [CrossRef] [PubMed]

78. Martel, M.O.; Jamison, R.N.; Wasan, A.D.; Edwards, R.R. The association between catastrophizing and craving in patients with chronic pain prescribed opioid therapy: A preliminary analysis. Pain Med. 2014, 15, 1757-1764. [CrossRef] [PubMed]

79. Hah, J.M.; Sturgeon, J.A.; Zocca, J.; Sharifzadeh, Y.; Mackey, S.C. Factors associated with prescription opioid misuse in a cross-sectional cohort of patients with chronic non-cancer pain. J. Pain Res. 2017, 10, 979. [CrossRef] [PubMed]

80. Sullivan, M.J.L.; Bishop, S.R.; Pivik, J. The Pain Catastrophizing Scale: Development and validation. Psychol. Assess. 1995, 7 , 524-532. [CrossRef]

81. Lai, H.M.X.; Cleary, M.; Sitharthan, T.; Hunt, G.E. Prevalence of comorbid substance use, anxiety and mood disorders in epidemiological surveys, 1990-2014: A systematic review and meta-analysis. Drug Alcohol Depend. 2015, 154, 1-13. [CrossRef] [PubMed]

82. Martins, S.S.; Fenton, M.C.; Keyes, K.M.; Blanco, C.; Zhu, H.; Storr, C.L. Mood and anxiety disorders and their association with non-medical prescription opioid use and prescription opioid-use disorder: Longitudinal evidence from the National Epidemiologic Study on Alcohol and Related Conditions. Psychol. Med. 2012, 42, 1261-1272. [CrossRef]

83. Goldner, E.M.; Lusted, A.; Roerecke, M.; Rehm, J.; Fischer, B. Prevalence of Axis-1 psychiatric (with focus on depression and anxiety) disorder and symptomatology among non-medical prescription opioid users in substance use treatment: Systematic review and meta-analyses. Addict. Behav. 2014, 39, 520-531. [CrossRef]

84. de Heer, E.W.; Gerrits, M.M.J.G.; Beekman, A.T.F.; Dekker, J.; van Marwijk, H.W.J.; de Waal, M.W.M.; Spinhoven, P.; Penninx, B.W.J.H.; van der Feltz-Cornelis, C.M. The association of depression and anxiety with pain: A study from NESDA. PLoS ONE 2014, 9, e106907. [CrossRef]

85. Grattan, A.; Sullivan, M.D.; Saunders, K.W.; Campbell, C.I.; Von Korff, M.R. Depression and prescription opioid misuse among chronic opioid therapy recipients with no history of substance abuse. Ann. Fam. Med. 2012, 10, 304-311. [CrossRef] [PubMed]

86. Gros, D.F.; Milanak, M.E.; Brady, K.T.; Back, S.E. Frequency and severity of comorbid mood and anxiety disorders in prescription opioid dependence. Am. J. Addict. 2013, 22, 261-265. [CrossRef] [PubMed]

87. Feingold, D.; Brill, S.; Goor-Aryeh, I.; Delayahu, Y.; Lev-Ran, S. Misuse of prescription opioids among chronic pain patients suffering from anxiety: A cross-sectional analysis. Gen. Hosp. Psychiatry 2017, 47, 36-42. [CrossRef]

88. Feingold, D.; Brill, S.; Goor-Aryeh, I.; Delayahu, Y.; Lev-Ran, S. The association between severity of depression and prescription opioid misuse among chronic pain patients with and without anxiety: A cross-sectional study. J. Affect. Disord. 2018, 235, 293-302. [CrossRef]

89. Rogers, A.H.; Bakhshaie, J.; Lam, H.; Langdon, K.J.; Ditre, J.W.; Zvolensky, M.J. Pain-related anxiety and opioid misuse in a racially/ethnically diverse young adult sample with moderate/severe pain. Cog. Behav. Ther. 2018, 47, 372-382. [CrossRef]

90. Van Rijswijk, S.M.; van Beek, M.H.C.T.; Schoof, G.M.; Schene, A.H.; Steegers, M.; Schellekens, A.F. Iatrogenic opioid use disorder, chronic pain and psychiatric comorbidity: A systematic review. Gen. Hosp. Psychiatry 2019, 59, 37-50. [CrossRef]

91. Baker, T.B.; Piper, M.E.; McCarthy, D.E.; Majeskie, M.R.; Fiore, M.C. Addiction motivation reformulated: An affective processing model of negative reinforcement. Psychol. Rev. 2004, 111, 33. [CrossRef] [PubMed]

92. McCarthy, D.E.; Curtin, J.J.; Piper, M.E.; Baker, T.B. Negative Reinforcement: Possible Clinical Implications of an Integrative Model. In Substance Abuse and Emotion; Kassel, K.D., Ed.; American Psychological Association: Washington, DC, USA, 2010; pp. 15-42. [CrossRef]

93. Evans, C.J.; Cahill, C.M. Neurobiology of opioid dependence in creating addiction vulnerability. F1000Research 2016, 5, 1748. [CrossRef]

94. Koob, G.F. Neurobiology of opioid addiction: Opponent process, hyperkatifeia, and negative reinforcement. Biol. Psychiatry 2020, 87, 44-53. [CrossRef] [PubMed]

95. Langdon, K.J.; Dove, K.; Ramsey, S. Comorbidity of opioid-related and anxiety-related symptoms and disorders. Curr. Opin. Psychol. 2019, 30, 17-23. [CrossRef]

96. Rogers, A.H.; Garey, L.; Bakhshaie, J.; Viana, A.G.; Ditre, J.W.; Zvolensky, M.J. Anxiety, depression, and opioid misuse among adults with chronic pain: The role of anxiety sensitivity. Clin. J. Pain 2020, 36, 862-867. [CrossRef]

97. Rogers, A.H.; Orr, M.F.; Shepherd, J.M.; Bakhshaie, J.; Ditre, J.W.; Buckner, J.D.; Zvolensky, M.J. Anxiety, depression, and opioid misuse among adults with chronic pain: The role of emotion dysregulation. J. Behav. Med. 2021, 44, 66-73. [CrossRef] [PubMed]

98. Kathryn McHugh, R.; Otto, M.W. Profiles of distress intolerance in a substance-dependent sample. Am J Drug Alcohol Abuse 2012, 38, 161-165. [CrossRef] [PubMed]

99. Ramírez-Maestre, C.; Reyes-Pérez, A.; Esteve, R.; López-Martínez, A.E.; Bernardes, S.; Jensen, M.P. Opioid Pain Medication Prescription for Chronic Pain in Primary Care Centers: The Roles of Pain Acceptance, Pain Intensity, Depressive Symptoms, Pain Catastrophizing, Sex, and Age. Int. J. Environ. Res. Public Health 2020, 17, 6428. [CrossRef] [PubMed]

100. McCracken, L.M.; Vowles, K.E. Acceptance and commitment therapy and mindfulness for chronic pain: Model, process, and progress. Am. Psychol. 2014, 69, 178. [CrossRef] [PubMed] 